Article

\title{
Perceived Exposure and Acceptance Model of Appearance-Related Health Campaigns: Roles of Parents' Healthy-Appearance Talk, Self-Objectification, and Interpersonal Conversations
}

\author{
Eunsoon Lee ${ }^{1(\mathbb{D})}$ and Gyu-il Lee ${ }^{2, *}$ \\ 1 Department of Media and Communication, Dong-A University, Busan 49236, Korea; eunslee11@gmail.com \\ 2 Department of Physical Education, Kyungpook National University, Daegu 41566, Korea \\ * Correspondence: mauri94@knu.ac.kr
}

check for

updates

Citation: Lee, E.; Lee, G.-i. Perceived Exposure and Acceptance Model of Appearance-Related Health

Campaigns: Roles of Parents'

Healthy-Appearance Talk,

Self-Objectification, and Interpersonal Conversations. Sustainability 2021, 13, 3445. https://doi.org/10.3390/ su13063445

Academic Editor: Ans Vercammen

Received: 30 November 2020

Accepted: 16 March 2021

Published: 19 March 2021

Publisher's Note: MDPI stays neutral with regard to jurisdictional claims in published maps and institutional affiliations.

Copyright: (C) 2021 by the authors. Licensee MDPI, Basel, Switzerland. This article is an open access article distributed under the terms and conditions of the Creative Commons Attribution (CC BY) license (https:/ / creativecommons.org/licenses/by/ $4.0 /)$.

\begin{abstract}
Excessive focus on appearance or lookism requires social attention as it can have negative consequences on individuals' psychological and mental states related to health and sustainable social practice. As part of a healthy and sustainable social practice, this study tests the mechanism of enhancing appearance-related health campaign's effectiveness through the O1-S-O2-R framework. Participants were 220 Korean college students with being 141 male and 78 female and they completed an on-line survey. The result of SEM analyses confirmed the O1-S-O2-R model. As the result of hypotheses testing, health campaign contents suggesting anti-lookism and diverse beauty standards have attracted the attention of people whose parents conversed using relatively less healthy-appearance talk when growing up and who had higher self-objectification scores with body surveillance and body shame. Interpersonal conversations and thoughts on the media content played a mediating role in the model, while health campaigns had a higher persuasive effect on campaign evaluation and the behavior intention of spreading the campaign's content. Implications of the findings were discussed regarding health campaign designers and individuals, including parents, in education settings.
\end{abstract}

Keywords: appearance-related health campaigns; parents' healthy-appearance talk; self-objectification; interpersonal conversations

\section{Introduction}

Sustainability can define as "maintaining well-being over a long, perhaps even an indefinite period (p. 3441)" [1]. Relating to psychological well-being, establishing a positive body image is an essential factor for an individual's health throughout their lives. Therefore, scholars need to examine possible denigrating versus protective factors to promote a healthy body image. Sustainable social practices such as public health campaigns, corporate social responsibility (CSR), educational plans, and policymaking around media should be advanced based on identified factors and mechanisms. Studies found that media, family, and peers' tripartite influence and idealizing media figures decrease body satisfaction [2-5]. Studies also reported that Korean youth were more susceptible to developing unrealistic standards for appearance and negative body image than U.S. youth [6,7]. The statistical report of the International Society of Aesthetic Plastic Surgeons (ISAPS) also revealed that South Korea ranked as one of the top five countries that performed the most cosmetic surgical and nonsurgical procedures, along with the U.S., Brazil, India, and Mexico in 2015 [8]. In this sense, the current study sampled Korean college students, and the findings of this study would merit understanding the phenomena related to appearance-related media use and media content acceptance. Excessive focus thin-ideal appearance or lookism requires social attention because it can negatively affect on individuals' psychological 
health such as self-esteem, body satisfaction, and eating disorders [2-5,9]. Concomitantly, possible ways to curve excessive focus can be sought by media campaigns and people around us to boost either one's positive body image or heighten the awareness of the dangerous effect of thin-idealization or unified beauty standards.

Media landscapes have become more diverse and complex with multiple channels and integrated devices such as the internet, SNS, and UGC (user-generated content) and the traditional media of magazines, television, and radio. It is not surprising, then, that a health communication campaign's effectiveness becomes a complex phenomenon, and scholars and public health professionals seek to explain how individuals consume media content outside a movement in the context of their everyday life. While many factors affect individuals' perceptions, attitudes, intentions, and behaviors around health $[10,11]$, the significance of interpersonal communication on health-related behaviors has gained specific attention recently $[10,12,13]$. Accordingly, this study aims to investigate the role of interpersonal communication in the cognitive mechanism of processing appearance-related health campaigns.

Interpersonal communication, either health-enhancing talk or health-threatening talk, has been tested as a mediator between media exposure and health-related behaviors such as physical activity [14], body dissatisfaction and eating disorders [15], smoking [16], perception of obesity [17], organ donation [18] and cosmetic surgery [19]. Most studies highlighting interpersonal communication's role in health campaigns adopted the Orientation1-Stimulus-Orientation2-Response (O1-S-O2-R) approach [20]. The O1-S-O2-R model explained the multi-faceted influence that comprises the antecedents and outcomes of the individual-level media complementarity of health information. Accordingly, this study follows the O1-S-O2-R model to investigate the role of interpersonal communication as both the antecedent and the mediator of campaign perception and evaluation. Specifically, this study examines the conceptual model of appearance-related psychological variables, including parent's healthy-appearance talk, perceived exposure to health-related campaigns, peer pressure, attitude toward media content, and behavioral intention to spread the content (reference Figure 1).

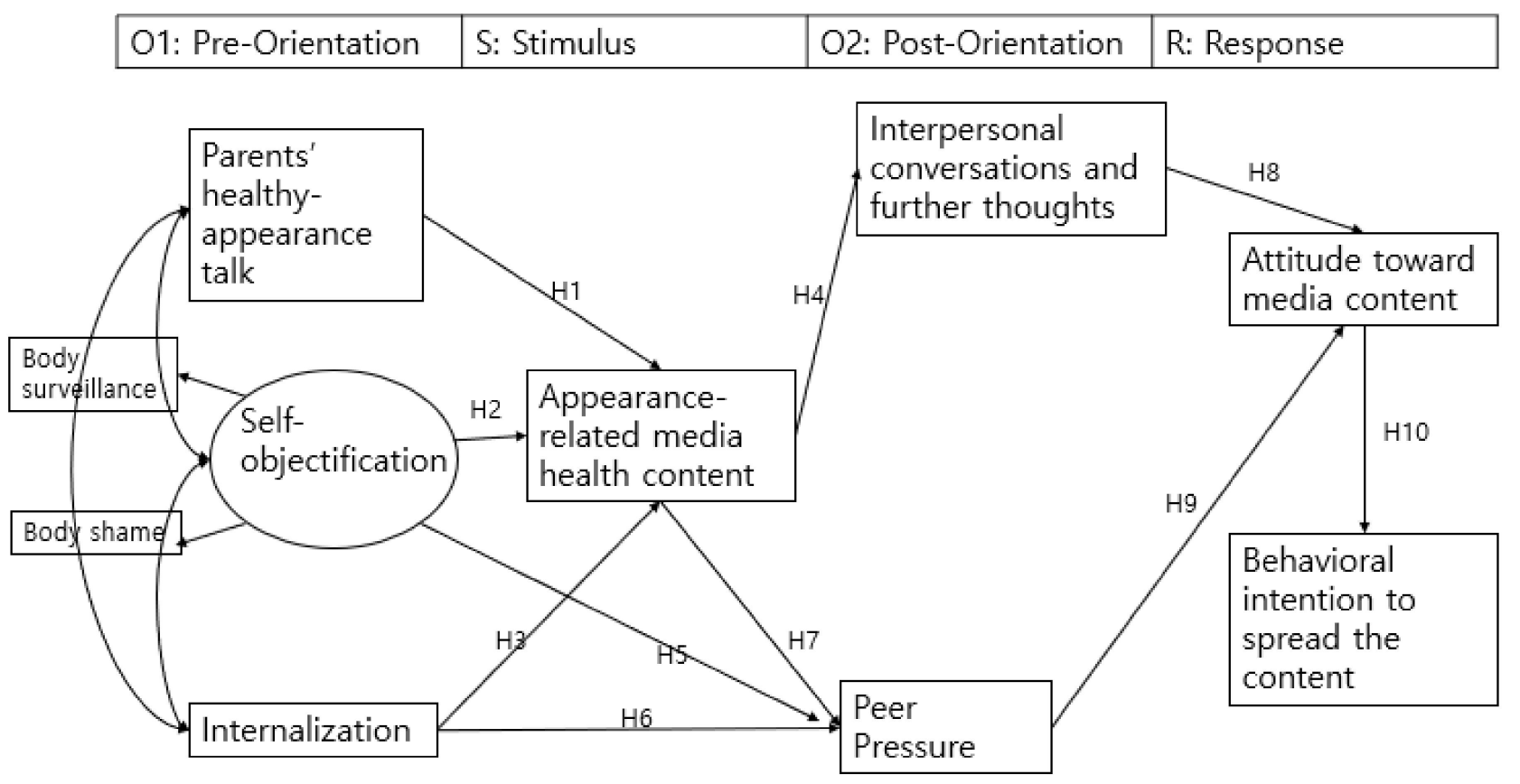

Figure 1. The proposed O1-S-O2-R model and hypotheses. 
This study also highlights the importance of the positive aspects of healthy-appearance talk and the beneficial role of the interpersonal conversation after exposure to campaign content. Although an increasing number of studies on health issues incorporates interpersonal communication in an everyday environment setting, few studies on health communication have explored the O1-S-O2-R process in an appearance-related health context. Fewer studies on body image have investigated the beneficial influence of media and positive factors in health media campaigns. Accordingly, this study attempts to identify pre-orientations of individuals that draw attention to health-promoting media campaigns and focuses on the role of interpersonal communication with parents and peers' pressure to promote or resist the effectiveness of health campaign content.

This study also incorporates self-objectification and internalization of appearance ideals as psychological orientations. In self-objectification theory, people internalize other's points of view when their appearance is evaluated [21,22]. The objectification of one's body often reflects the omnipresent images of the media's thin-ideal and sexualized models [23-25]. In the process of self-objectification, the tripartite influences of media, family, and peers are involved in forming body image and behavioral consequences [2-5,9]. Thus, to promote a healthy body image, this study seeks to find ways to alleviate lookism and grasp media and communication's plausibly positive function. Distributing such campaigns, social movements, and educational instructions can improve an individual's psychological wellbeing and build a sustainable society.

\section{Literature Review}

\subsection{O1-S-O2-R Model}

Instead of the traditional stimuli-response model (S-R model) in social psychology, Markus and Zajonc [11] present the O1-S-O2-R model, highlighting "cognitive" elements between classical activism stimuli and responses. McLeod and his colleagues [26,27], who first introduced the O1-S-O2-R model to mass media research, explain that in the O1-S-O2-R model, human orientation affects the interpretation and attention of stimuli and also goes through a cognitive process before action or change of attitude. That is, various individual characteristics (O1) affect the perception of media content (S) and, again, between media stimuli (S) and responses (R), the media's indirect influence is formed through the medium of interpersonal communication and cognitive deliberation as another orientation $(\mathrm{O} 2)$ to issues by message processing.

In the early days of the O1-S-O2-R model, communication scholars verified the model by dealing with political issues [28]. Recently, however, scholars have expanded the model's application into various areas such as environmental issues [29] and health issues [14,16-18,30].

In this model, the first orientation (Orientation1) acts as individual characteristics, such as gender, age, personality, etc., and as a level of interest or knowledge in a particular health issue or behavior, which affects exposure to health-related messages and related media content (Stimulus). The exposure of specific media content or messages will then affect the second orientation (Orientation2) of thinking about or talking about health issues, followed by the intention or behavior (Response). Thus, the model verifies the effects of personal factors on media perception and tests the direct and indirect effects of media and conversation's mediating role.

\subsection{Body Image}

Studies on body image have reported that appearance supremacy, so-called lookism, is influenced both by the media and the people around the individual [15,31,32]. Past studies on the Tripartite Influence Model tend to focus on three primary sociocultural influences-parents, peers, media-and two proposed mediators-internalization of appearance ideals, social comparison-as potential antecedents of body dissatisfaction and eating disorders [33-36]. Moreover, the self-objectification theory explains that continuing to objectify one's body through other people's eyes or internalizing society's aesthetic standards 
can result in eating disorders and excessive dieting along with psychological discomfort and dissatisfaction experiences $[21,22,24,25]$.

Guided by the two models, the present study identified the three orientations (O1) that can influence the selective perception of exposure to media health campaigns on body image. Pre-orientation (O1) refers to "the set of structural, cultural, cognitive, and motivational characteristics the audience brings to the reception situation that affects of the impact of messages of the impact of messages (p. 238)" [25]. In this study, the three factors of pre-orientation (Orientation1) are parents' healthy appearance talk, self-objectification, and internalization as cultural/motivational ones.

\subsection{Variables of OSOR Model}

\subsubsection{Orientation1-1: Parent's Healthy-Appearance Talk}

Fat talk is a form of both other-disparaging and self-denigrating remarks in that the speaker typically criticizes his or her body weight, shape, or physical fitness [37]. Fat talk, particularly between family members, was found to impact disordered eating profoundly [38]. Although the pervasive nature of fat talk in modern cultures and its negative effects have been well-documented [39,40], some scholars speculate that curbing fat talk may be difficult in practice because fat talk is a socially normative response [41,42].

Thus, the present study advances the concept of healthy-appearance talk rather than fat talk or age talk, which typically convey negative comments on one's look. Healthyappearance talk can be defined as "communication that mentions appearance based on physical health and mental health rather than the social standard of beauty and the value of social gain (p. 149)" [19]. Accordingly, healthy-appearance talk taps the perspectives of accepting various beauty types, focusing on health and inner beauty rather than the ideal body/face shape, and emphasizing one's appearance pride or "perfect" body. Given that family factors in body talk have been linked to media use and body image [38,39,43], the present study examines the relationship between a healthy-appearance talk with parents and brings attention to appearance-related media contents of health campaigns.

\subsubsection{Orientation1-2: Self-Objectification}

In this study, appearance-related psychology comprises self-objectification and internalization. According to self-objectification theory, people tend to internalize others' points of view when they are regularly exposed to others' evaluations of their own body [21,44]. The phenomena in which people project others' views on their own bodies as their thoughts are called self-objectification. Individuals who have experienced self-objectification for a long time tend to have body-surveillance and body-shame. Body surveillance is related to self-consciousness characterized by persistent body monitoring or a stream of consciousness on one's body. When people are consistently concerned about their body on display, they often compare their bodies to unattainable cultural ideals and thus experience body shame.

\subsubsection{Orientation1-3: Internalization of Appearance Ideals}

The objectification of one's body often reflects the omnipresent images of the media's thin-ideal and sexualized models [23]. The internalization of the "thin-ideal" is theorized to be a critical factor in the past literature [45-47]. The thin ideal media exposure tends to drive this internalization among adolescents [24,25], and, in turn, girls' body dissatisfaction and eating disorders $[31,34]$. The sociocultural framework has been supported by boys as well [36]. Thus, chronic body surveillance promotes feelings of body shame when one falls short of one's internalized and unrealistic standards [36].

This sociocultural approach of appearance ideals is one of the most widely used explanations, focusing on the influences of parents, peers, and the media on young people's body image [36]. Although this approach often highlights the internalization of appearance ideals as a mediator between societal influences of peers, parents, and media and body 
image $[9,36,46]$, the present study included internalization as a preorientation factor a motivational characteristic.

\subsubsection{Stimulus: Perceived Exposure to Media Contents of Appearance-Related Health Campaign}

Although new media, including the mass media, have reported adverse effects on body image and eating behaviors, it is not without health campaigns or movements to improve awareness of the "thin-ideal" image and self-objectification mechanism in society. For example, there are campaigns such as the Body Positive movement, No Fat Talk week, and the Real Beauty project that have been carried out by social activists such as feminist groups and companies for a decade. The Real Beauty project, as an instance, was launched by Dove, and a series of videos have featured real people rather than professional models to showcase women of different sizes and different skin colors [48,49]. Although some campaigns have sparked feelings of skepticism, exposure to models who look like ordinary women in Dove's "Real Beauty Campaign" helps reduce viewer's perceived discrepancy between themselves and the perfect look, which further restores and enhances their positive self-views [48,50,51]. Other campaigns such as the Body Positive movement, Corset-Free, and the Plus-Size Model movement also attempt to promote women's self-esteem through diverse beauty standards, and other campaigns such as the No Fat Talk campaign aim to curve excessive fat talk as a social norm.

In South Korea, there have been social movements that had changed the media environment. In response to social activists, public television broadcasting systems abolished the annual airing of beauty peasant contests such as Miss Korea, and reality makeover shows in early 2010. In 2019, the Ministry of Gender Equality of Family officially proposed "gender equality guidelines for the production of broadcasting programs" that avoid directing and expressing uniform appearance standards on screen.

Such campaigns and movements have reflected social needs in diversity appearance reenactments, raising awareness of anti-lookism and pinpointing excessive focus on looks. This study aims to address how much attention or perception is given to multiple media contents that counteract lookism or present problems of uniformed aesthetic standards as a media stimulus. When diverse information is available in various media channels, this does not guarantee that a person's views will be equally diverse or congruent with the advocated position. According to selective exposure theory, people differently attend to the same information based on either defense motives or accuracy motives in a situation of between congenial information (congruent to pre-existing attitudes) versus uncongenial information (challenging to pre-existing attitudes) [52]. When activated by defense motivation, people tend to better attend to and memorize congenial information than uncongenial information. However, when accuracy motivation was related to accomplishing a current goal and uncongenial (incongruent to pre-existing) information was relevant to the goal, people perceived the uncongenial information well. Moreover, a series of studies have shown that people are most likely to recall information that violated their expectations [53-55]. In this sense, people who are highly sensitive to appearance cues in society and motivated to accept the views of relieving their dissonant state of mind between the ideal and the actual can be those who are highly self-conscious of their body rather than those who have relatively stable and healthy views on their body.

Traditionally, targets of health campaigns are those who suffer from designated health problems. In this sense, media content that raises issues of the "thin-ideal" image or pervasive consensus on lookism should capture attention from people who suffer from unhealthy body image from parents, media, and peers $(\mathrm{O} 1 \rightarrow \mathrm{S})$. Thus, healthy-appearance talk with parents predicts a negative association with the perception of health campaigns because these people are less motivated to defend their position, thus less perceiving congruent content with their pre-existing attitudes. In contrast, self-objectification and internalization predict positive associations with perceived exposure to health campaigns because they are highly motivated and activated to perceive appearance cues in society and anti-lookism health campaigns are incongruent to their attitudes. Those who are high 
in self-objectification and internalization may memorize or recall information of these contents better.

H1: Parents' healthy-appearance talk will be negatively associated with perceived exposure to media contents of appearance-related health campaigns.

H2: Self-objectification will be positively associated with perceived exposure to media contents of appearance-related health campaigns.

H3: Internalization will be positively associated with perceived exposure to media contents of appearance-related health campaigns.

\subsubsection{Orientation2-1: Interpersonal Conversations and Thought Deliberation}

Post-orientation $(\mathrm{O} 2)$ is defined as "various ways audiences may deal with media messages and indicates which is likely to happen between the reception of messages and the subsequent response or outcome (p. 239)" [26]. In this study, interpersonal communication and deliberation on campaigns are conceptualized as the post-orientation variables.

Individuals learn from what they see and hear on media from the cultivation theory [56]. Once they are exposed to specific media content, they tend to talk and think about that content $[14,26,57-60]$. Past studies show that conversation and thoughts can amplify or suppress mass media effects, leading to positive or negative outcomes [59]. For example, people who have conversations with friends and family about quitting smoking are more likely to try to quit smoking [60]. Conversations about health advertisements can spread campaign messages to the target audience [57]. Regarding thoughts, past studies also show that reflective integration mediates the relationship between media exposure and knowledge [58], intention [61], and behavior [14,58]. Therefore, this study expects higher levels of exposure to appearance-related health campaigns to be associated with more interpersonal conversations and more thoughts about media content.

H4: Perceived exposure to media contents of appearance-related health campaigns will be positively associated with interpersonal conversations and thoughts on media content.

\subsubsection{Orientation2-2: Peer Pressure}

Meanwhile, adolescents and college students are known to be susceptible to peer perceptions [62]. Since they are concerned with the impressions they make on peers, much of the research on risky health behaviors has demonstrated the perceived peer norm is a major determinant of their attitude and behavior [16].

Previous research shows that peer influences have been linked with body dissatisfaction and eating disorders. Peer pressure for thinness predicted body dissatisfaction among adolescent girls [63], and peer competition, but not television effects, predicted body dissatisfaction in adolescent girls [64]. Among early teenage girls, appearance-related discussion with their friends predicted watching tween TV programs more frequently six months later, and both media exposure and peer conversation were related to the internalization of appearance ideals [65]. Thus, peer pressure would be positively related to self-objectification tendency and internalization. Although there is little evidence on relationships between peer pressure and perceived exposure to media contents of appearance-related health campaigns, media information inconsistent with peer pressure would have a negative impact on peer pressure.

H5: Self-objectification will be positively associated with peer pressure.

H6: Internalization will be positively associated with peer pressure.

H7: Perceived exposure to media contents of appearance-related health campaigns will be negatively associated with peer pressure. 


\subsubsection{Response(R): Attitude and Behavioral Intention}

Attitude toward appearance-related health campaigns refers to an individual's overall evaluation of media contents of health campaigns and social movements. As most persuasion studies demonstrate that attitude shapes one's behavior, the attitude toward media campaigns will be a predictor of the behavioral intention to spread the campaign messages [57]. As noted, this study examines how media and communication interactively affect social issues by looking at the attitudes and needs of these alternative movements and the intentions of spreading this awareness.

H8: Interpersonal conversations and thoughts on media content will be positively associated with attitude toward the campaign.

H9: Peer pressure will be negatively associated with attitude toward the campaign.

H10: Attitude toward the campaign will be positively associated with behavioral intention to spread the awareness of campaigns.

\subsubsection{Proposed O1-S-O2-R Model}

The proposed OSOR model denotes that parents, self-objectification, and internalization of thin-ideal images affect the perception of media campaigns promoting healthy body image, which in turn affects interpersonal conversations and thoughts on media contents and peer pressure, and the two mediators consequently affect the persuasive effects of campaign movement. Figure 1 shows the path model of each hypothesis.

\section{Materials and Methods}

\subsection{Participants and Procedure}

Originally, 265 college students participated in this study. Because this study used a general attitude about appearance-related campaigns and the intention to spread the awareness of the campaign as outcome variables, 45 participants who were not exposed to the campaigns were excluded from the analysis. The participants were 220 Korean college students with 141 males and 78 female students (one missing) aged 21.3 years $(M=21.3, S D=1.84)$. Participants were recruited through class fliers in two universities in South Korea and completed an on-line survey with the exchange of extra credits for class participation. Participation was voluntary. Seventy-one participants (32\%) identified as freshmen, with others reporting to be 51 sophomores ( $23 \%), 62$ juniors ( $28 \%), 35$ seniors $(16 \%)$, and 1 other $(0.5 \%)$.

\subsection{Measures}

\subsubsection{Measures of O1-S-O2-R Variables}

In terms of exposure to appearance-related health campaigns and social movements (Stimuli), selective exposure to media health campaigns on body image was measured using an eleven-item scale including three general questions and eight specific questions. Self-reported exposure to campaign messages and the aided recall measures were employed to measure health campaign exposure based on previous studies $[16,66,67]$. Three general items were modified from previous O1-S-O2-R research, asking the participants whether they had ever heard of or had been exposed to media content about (a) anti-lookism, (b) diversity of beauty standards, and (c) excessive appearance consciousness at a societal -level of problems. Eight specific recalled items asked the participants whether they know / have heard of (a) the Body Positive Campaign, (b) the Real Beauty Project by the DOVE company, (c) the No Fat Talk campaign, (d) the Corset-Free Movement, (e) employment of Plus-Size Models, (f) the movement of abolishing makeover reality TV programs or cosmetic surgery reality shows, $(\mathrm{g})$ the movement of banning beauty peasant contests from being on-air in public TV programs, (h) the news of "gender equality guidelines for making shows" by the Ministry of Gender Equality of Family. Responses were anchored with a four-point Likert scale from never heard of (1), briefly heard of (2), heard it by paying attention to (3), to know it very well (4). Additionally, one open question was asked to list any campaign 
or media program that changed their traditional views on beauty or appearance awareness. For this study, the 11-item scale showed good reliability (alpha $=0.89)$.

For healthy-appearance talk with parents(O1-1), parents' talk about healthy appearance was measured using an eight-item healthy-appearance talk scale based on Lee [19]. This study added one reversed item from the original scale, asking the amount of talk as "My parents often talk about appearance." This current study also anchored "When I grew up, ... " before asking about the healthy-appearance talk of parents. Respondents used a five-point Likert scale, ranging from strongly disagree (1) to strongly agree (5), to rate items such as "When I grew up, my parents had said that a healthy body looks better than a skinny body" and "When I grew up, my parents have told me that I am beautiful/cool regardless of social standards". Cronbach's alpha for eight items was 0.82 .

Self-objectification (O1-2) was measured using a four-item Body Surveillance subscale and a five-item Body Shame subscale of the Objectified Body Consciousness Scale [68,69]. Respondents used a five-point Likert scale, ranging from strongly disagree (1) to strongly agree (5), to rate items such as "During the day, I think about how I look many times." Cronbach's alpha for four-item body surveillance was 0.82 , and alpha for five-item body shame was 0.80 .

Internalization (O1-3) of appearance ideals was measured using an eight-item subscale of the Sociocultural Attitudes Towards Appearance Questionnaire-Version 3 [22]. Respondents used a five-point Likert scale, ranging from strongly disagree $(=1)$ to strongly agree $(=5)$, to rate items such as "I compare my body to the bodies of TV and movie stars". In this study, one item showed poor fit; thus, seven items were used for analysis. Cronbach's alpha for seven items was 0.87 .

Interpersonal conversation and further thoughts (O2-1) about appearance-related campaign content were measured using a three-item scale modified from previous studies [28]. Respondents used a five-point Likert scale, ranging from strongly disagree (1) to strongly agree (5), to rate items such as "After I was exposed to awareness campaigns or programs for healthier appearance, I have talked and discussed the content," and "After I was exposed to awareness campaigns or programs for healthier appearance, I have thought further about the content." Cronbach's alpha for three items was 0.82 .

For Peer Pressure (O2-2)was measured using a three-item scale in order to capture peer norms on appearance. Respondents used a five-point Likert scale, ranging from strongly disagree (1) to strongly agree (5), to rate items such as "Now, friends and peer around me think that appearance including facial look, body shape, and fashion styles are very important." Cronbach's alpha for three items was 0.78 .

For attitudes toward the campaigns and behavioral intention (R), the general attitude toward awareness campaigns on healthier appearance was measured using a three semantic scale: very negative (1) to very positive (5), hardly persuasive (1) to very persuasive (5), and very ineffective (1) to very effective (5). Cronbach's alpha for three items was 0.85. A one-item measure was used to assess participants' intention to talk about the content of campaigns or to recommend to friends and family members by sharing the link with SNS.

\subsubsection{Additional Measures}

Although the present study does not focus on lifestyle change after COVID-19, the change in interaction with family and friends can provide insight into this study. Two additional questions about the change in time spent with parents and friends were measured: "How much have you changed in spending time with your parents after a breakout of COVID-19?" and "How much have you changed in spending time with your friends after a breakout of COVID-19?". Respondents used a five-point Likert scale, ranging from reduced very much (1), reduced (2), equal as before (3), increased (4) to increased very much (5). Demographic variables, including sex, age, and year in college, were also asked in the questionnaire. 


\section{Results \\ 4.1. Preliminary Analyses}

Prior to the main analysis, all the scales were checked for normal distribution, skewness, and kurtosis statistics. Based on reliability, all the items were pre-screened and produced the average value for SEM analysis. A correlation matrix and means and standard deviations (S.D.s) for all variables are provided in Table 1. Means and S.D.s for exposure to 11 specific campaigns and time changes with people after COVID-19 are also provided in Table 2.

Table 1. Values of correlation, means, and standard deviation.

\begin{tabular}{|c|c|c|c|c|c|c|c|c|c|c|c|}
\hline & (1) & (2) & (3) & (4) & (5) & (6) & (7) & (8) & (9) & (10) & (11) \\
\hline 1. Year in college & 1 & & & & & & & & & & \\
\hline 2. Sex & $0.19 * *$ & 1 & & & & & & & & & \\
\hline 3. Parents' talk & $-0.20 * *$ & -0.06 & 1 & & & & & & & & \\
\hline 4. Body surveillance & 0.03 & $0.15 *$ & -0.05 & 1 & & & & & & & \\
\hline 5. Body shame & 0.05 & 0.17 * & $-0.31 * * *$ & $0.46^{* * *}$ & 1 & & & & & & \\
\hline 6. Internalization & $0.16^{*}$ & $0.44^{* * *}$ & $-0.30 * * *$ & $0.44^{* * *}$ & $0.61 * * *$ & 1 & & & & & \\
\hline 7. Exposure to campaign ${ }^{\text {a }}$ & $0.25 * * *$ & $0.32 * * *$ & $-0.34^{* * *}$ & 0.14 * & $0.26^{* * *}$ & $0.20 * *$ & 1 & & & & \\
\hline 8. Conversation & $0.18^{* *}$ & $0.22 * *$ & $-0.24^{* * *}$ & $0.33^{* * *}$ & $0.17^{*}$ & $0.22 * *$ & $0.53^{* * *}$ & 1 & & & \\
\hline 9. Peer pressure & 0.02 & 0.01 & -0.17 * & $0.36^{* * *}$ & $0.33^{* * *}$ & $0.28 * * *$ & $0.14 *$ & $0.20 * *$ & 1 & & \\
\hline 10. Attitude & 0.07 & $0.23 * *$ & 0.03 & 0.08 & -0.11 & 0.10 & $0.32 * * *$ & $0.44^{* * *}$ & -0.01 & 1 & \\
\hline 11. Behavioral Intention & -0.11 & $0.19 * *$ & -0.03 & 0.07 & 0.03 & 0.13 & $0.29 * * *$ & $0.35^{* * *}$ & 0.03 & $0.64^{* * *}$ & 1 \\
\hline$M$ & 2.29 & 1.36 & 4.05 & 3.28 & 2.25 & 2.56 & 18.45 & 2.52 & 2.85 & 3.41 & 3.13 \\
\hline$S D$ & 1.10 & 0.48 & 0.59 & 0.77 & 0.85 & 0.90 & 5.79 & 0.90 & 0.80 & 0.62 & 0.92 \\
\hline alpha & - & - & 0.81 & 0.82 & 0.80 & 0.87 & 0.89 & 0.84 & 0.78 & 0.85 & - \\
\hline
\end{tabular}

Note: ${ }^{*} p<0.05,{ }^{* *} p<0.01,{ }^{* * *} p<0.001$; sex 1 as male and 2 as female; variables 3 to 11 are all measured with a five Likert scale except ${ }^{\text {a }}$.

${ }^{a}$ variable comprises a composite value of 11 items of exposure to campaign content.

Table 2. Descriptive statistics of exposure to campaign contents and change in time spending.

\begin{tabular}{|c|c|c|c|}
\hline & $\mathbf{M}$ & SD & Range \\
\hline 1. Exposure to anti-lookism content & 1.79 & 0.69 & $1 \sim 4$ \\
\hline 2. Exposure to diversity in beauty standards & 2.06 & 0.87 & $1 \sim 4$ \\
\hline 3. Exposure to problems in excessive focus on the look & 2.18 & 0.79 & $1 \sim 4$ \\
\hline 4. Exposure to Body Positive campaign & 1.46 & 0.69 & $1 \sim 4$ \\
\hline 5. Exposure to a Real Beauty campaign & 1.30 & 0.59 & $1 \sim 4$ \\
\hline 6. Exposure to No Fat Talk campaign & 1.36 & 0.67 & $1 \sim 4$ \\
\hline 7. Exposure to Corset-Free movement & 2.16 & 0.93 & $1 \sim 4$ \\
\hline 8. Exposure to Plus Size model movement & 1.76 & 0.96 & $1 \sim 4$ \\
\hline 9. Exposure to banning makeover shows on air & 1.51 & 0.74 & $1 \sim 4$ \\
\hline 10. Exposure to banning beauty contests on air & 1.51 & 0.75 & $1 \sim 4$ \\
\hline 11. Exposure to official appearance guideline on air & 1.35 & 0.65 & $1 \sim 4$ \\
\hline Change in time spent with parents after COVID-19 & 3.41 & 1.00 & $1 \sim 5$ \\
\hline Change in time spent with friends after COVID-19 & 2.66 & 1.07 & $1 \sim 5$ \\
\hline
\end{tabular}

Note: Greater numbers in exposure mean more exposure to the content; Greater numbers in time change mean increased time spent after Covid-19.

The hypothesized model was tested using SPSS Amos software. Model fit can be tested using the statistics of chi-square, minimum discrepancy per degree of freedom $(\mathrm{CMIN} / d f)$, comparative fit index $(\mathrm{CFI})$, the normed fit index (NFI), the root mean square error of approximation (RMSEA), and the standardized root means square residual (SRMR). $\mathrm{CMIM} / d f$ values of below 3 represent an acceptable fit, and values of below 5 represent a reasonable fit, and a RMSEA value of 0.05 and lower, represents a good fit, 0.05 to 0.08 represents acceptable fit. CFI and NFI values greater than 0.95 represent a good fit between the model and data. SRMR was used to evaluate the proposed and reduced models because unequal ranges of scales were used in the analysis and a value between 0.05 and 0.08 for SRMR represents an acceptable and marginal fit [70]. 


\subsection{Structural Model Testing}

The proposed model showed a marginal fit based on multiple goodness of fit indexes, $\chi^{2}(21)=73.344, p=0.000, \mathrm{CMIN} / d f=3.493, \mathrm{RMSEA}=0.11, \mathrm{NFI}=0.87, \mathrm{CFI}=0.90$, and $\mathrm{SRMR}=0.07$. To strengthen the interpretation of results and further investigate other relations among variables in the model, the modification indices pertaining to the covariances and the regression weights were reviewed to look for areas of better model fit. The major modification index was associated with the covariances with measured variables of self-objectification - body surveillance and body shame - and a path was added from self-objectification to interpersonal conversation. The path between self-objectification and interpersonal conversation, however, was not significant $(\beta=0.114, p=0.092)$. As the proposed model assumed, in the revised model parents' healthy-appearance talk was negatively correlated with both self-objectification $(r=-0.31, p<0.001)$ and internalization $(r=-0.30, p<0.001)$. Self-objectification showed a strong positive correlation with internalization $(r=0.76, p<0.001)$. Added to the model, body surveillance was positively correlated with interpersonal conversation and thought $(r=0.28, p<0.001)$ and body shame was negatively correlated with attitude toward campaign content $(r=-0.30, p<0.001)$. The results of correlations in the model would be beneficial to discussion and suggestions for future research. Overall, the modification of the model improved the values of NFI and CFI and dropped the chi-square value. The final model is presented in Figure 2. The model showed a better fit, $\chi^{2}(20)=39.750, p=0.005, \mathrm{CMIN} / d f=1.987, \mathrm{RMSEA}=0.067$, $\mathrm{NFI}=0.930, \mathrm{CFI}=0.963, \mathrm{SRMR}=0.05$.

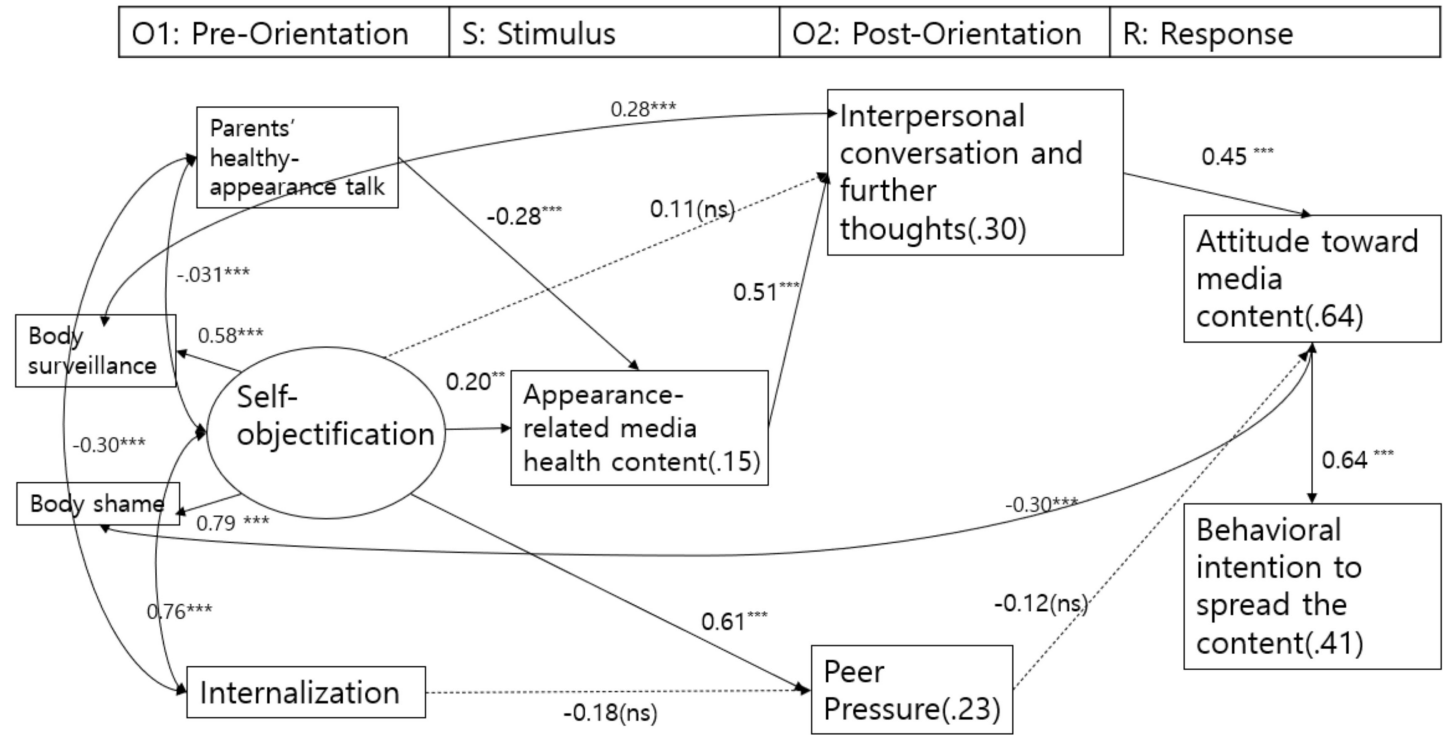

Figure 2. The final model $(N=220)$. Note: All the coefficients are completely standardized. Numeric values in parentheses indicate total variance explained. ${ }^{* *} p<0.01,{ }^{* * *} p<0.001$.

All hypotheses except Hypothesis 3, 6, 7, and 9 were supported. Parents' healthyappearance talk $(\beta=-0.28, p<0.001)$ and self-objectification $(\beta=0.20, p<0.01)$ were associated with exposure to appearance-related health campaigns, supporting $\mathrm{H} 1$ and $\mathrm{H} 2$. Meanwhile, internalization of media ideals was neither associated with campaign exposure $(\beta=-0.13, p=0.362)$ nor with peer pressure $(\beta=-0.18, p=0.178)$, rejecting H3 and H6. Exposure to health campaigns had a positive effect on interpersonal conversation and further thoughts $(\beta=0.51, p<0.001)$, supporting $\mathrm{H} 4$, whereas exposure to health campaigns was not associated with peer pressure $(\beta=-0.02, p=0.785)$, rejecting H7. Self-objectification had a strong positive effect on peer pressure $(\beta=0.61, p<0.001)$, supporting H5. Interpersonal conversation and thoughts, in turn, had a positive effect on attitude $(\beta=0.45, p<0.001)$ and attitude positively predicted behavioral intention ( $\beta=0.64$, 
$p<0.001$ ), supporting H8 and H10. Peer pressure marginally failed to have a negative impact on attitude $(\beta=-0.12, p=0.054)$, rejecting $\mathrm{H}$ 9.

\section{Discussion}

The present study tested the O1-S-O2-R model as a process of attending to appearancerelated health campaigns and strengthening the effectiveness of health campaigns to sustain a positive body image and promote psychological well-being. Grounded on selfobjectification theory and the tripartite influence model of body image, this study hypothesized the influence of parents and appearance-related psychology on selective exposure to health campaigns and peer pressure as a resistant factor against campaign persuasion. As the OSOR model suggested, the study also hypothesized that interpersonal conversations and thoughts mediate media exposure's influence on campaign effects.

The results show that media contents suggesting anti-lookism and diverse beauty standards have drawn attention from people whose parents used relatively less healthyappearance talk when growing up and who had higher scores in self-objectification with body surveillance and body shame. These findings were consistent with the previous studies, illuminating the significant role of family factors $[19,22,31,38,39,71-73]$ in the theoretical framework of self-objectification $[24,25,46,47]$. From the perspective of health campaign design, health issues should draw the attention of people in need. The findings show individuals who suffer from problematic body image regarding self-objectification, as well as insufficient healthy-appearance talk with parents, pay more attention to targeted health campaigns and social movements.

Furthermore, the current findings replicate recent work in the O1-S-O2-R tradition $[14,16-18,30]$, indicating that health campaigns are associated with more positive attitudes and behavioral intention. That is, individual intention to spread health campaign content is influenced by exposure to such campaigns. Exposure to various campaign contents depended on the individual's susceptibility as a function of psychology based on their own body and a function of their family communication environment. The proposed model was changed to include the path between self-objectification and interpersonal conversation. However, the fact that the path was not significant $(\beta=0.114, p=0.092)$ seems to confirm the O1-S-O2-R model, since the O1 variables (parents' talk and self-objectification) work through the stimulus (exposure to campaigns) to be associated with conversation about and cognition of the media content as the $\mathrm{O} 2$ variable. Although this study did not directly test the mediation effect, the fit of the final model and the significance tests of path coefficients confirmed the usefulness of the O1-S-O2-R model.

The current findings extend the work in this area by finding that interpersonal communication plays an important role $[10,13,14,60]$. As the O1-S-O2-R model suggests, when considering interpersonal conversations and thoughts on media content, media content, including health campaigns and social movement on body image, had a higher persuasive effect on campaign evaluation and the behavior intention of spreading the campaign's content. This result of the mediation effect indicates how media campaigns can increase their impact with education settings, providing all the possible discussion opportunities or environment both at home and at school.

Although the internalization of sociocultural attitudes was positively associated with self-objectification tendencies, it did not affect the perceived exposure to appearance-related health campaigns. Given that past studies dealt with the internalization of appearance ideals as a mediator between societal influences of peers, parents, and media and body image $[9,19,36,46]$, the present model might fail to capture the causal mechanism of internalization. Unlike a previous study on anti-smoking health campaigns among adolescents [16] and on peer influence on body image $[63,64]$, peer pressure in this study was neither affected by exposure to appearance-related health campaigns nor affected the process of the persuasive effect of the campaigns. This result suggests that once individuals perceive appearance-related movements, they are less affected by peer norms in processing the message. Although the current study was conducted among college students who are rela- 
tively less affected by peer norms than adolescents, the different subject matter-promoting healthier body image versus preventing smoking-might cause the different paths toward the effectiveness of persuasion. However, the inconsistent results might be caused because the measurement in this study was limited. Additional measures of peer pressure or peer communication [25] would merit future research. Moreover, the fact that students have drastically increased the time spent with parents than with friends after COVID-19, the findings of this study may be interpreted as such. The more substantial influence of parents than peers might result from this specific situation; thus, replication studies are required to support this study's results.

\subsection{Implications}

The results suggest several implications for health communication practitioners. First, health practitioners should consider using various media content types as ways to increase awareness of a healthy body image rather than the thin-ideal body image. The results of the mean scores in perceived exposure to media content, presented in Table 2, showed that exposure to most anti-lookism content was below the midpoint, which urges campaign designers and educators to promote appearance-related health campaigns. For example, campaign intervention techniques that lower the excessive focus on appearance in public (body surveillance), increase positive body-esteem (fix body shame), and increase health awareness rather than lookism among families and friends can be considered. A broad array of appearance-related media content and campaign will benefit various segmentations of people. As the revised model in this current study shows, body surveillance and body shame had different associations with conversation and attitude in the model. These disparaging results seem to hint that campaign content needs to be tailored to different target groups.

Second, the findings of this study also suggest that conversations play a special role both in pre-orientation and in encouraging healthy behaviors. Both family-focused and education-focused directions for prevention and intervention among students could be advanced. First, from an early stage, parents should redirect children's attention centered on weight, body shape, or face look toward health-focused beauty, including the sound psychological states of their children. In the current surroundings with COVID-19, when college students have had increased interaction with parents, the current sample reported that they have experienced highly positive appearance-related talks with their parents while growing up. The healthy-appearance talk with their parents was 4.05 on average with 5 being the maximum. The current finding that children had positive appearance talk with their parents should be replicated in future studies to build a sustainable practice in appearance-related social issues.

Third, students can learn how to regulate their own interactions and reactions within everyday media contexts as beneficial resources in educational settings. In fact, some interventions with feminist and ecological foci have been effective in educational settings against the harmful effects of the media on body image [74]. Although the present study did not find a significant effect of peer pressure, schools may design interventions that draw awareness of both overt and subtle pressures for thinness within peer settings.

In sum, when designing an intervention for healthy body image, parents need to be addressed as an important role from the start. Parent education should incorporate ways to reduce fat talk and increase health-focused talk. If individuals are already adults, the intervention of discussion or conversation after campaigns should be considered through clinical endeavors and school education. These conversations do not necessarily have to be about changing their behaviors or perceptions immediately because even conversations about appearance-related media content influence attitudes. Conversation or discussion on media content would be less intimidating than addressing changing attitudes and behaviors. Thus, conversations about appearance-related media content could be a good start for a potential intervention strategy. 


\subsection{Limitations}

The present study has several limitations. First, similar to many other O1-S-O2-R studies, this study is also based on cross-sectional data; thus, causality claims should be limited. Future studies need to design experimental settings or collect longitudinal data to make a causal inference. Second, although the present study addressed the effectiveness of health campaigns as the evaluation and intention to spread information, the actual benefits of health campaigns to individuals have not been tested, such as healthier selfperception, self-acceptance, and pursuing a healthy lifestyle. Thus, the implications of this study are limited to interpreting how health campaigns are effective in terms of campaign perception rather than how to improve an individual's perception. Third, measures of peer pressure and interpersonal communication need calibration in future studies. This study had only three items, both for peer pressure and interpersonal communication, although the reliability is decent. Future studies should use a different approach in scale or include instruments with more dimensions. For instance, peer pressure originates from various cognitive levels such as the perceived pressure to be thin from peers [63], and the perceived friend preoccupation with weight and dieting [75], as well as behavioral perception with peer criticism [25] and teasing scale [76].

\subsection{Conclusions}

In conclusion, the current findings contribute to our understanding of the cognitive mechanism of appearance-related health campaigns by identifying who attends to the campaign content and how the effect of campaigns can increase. The results show that individuals who suffer from self-objectification and have grown up in a family environment lacking healthy-appearance talk can actively pursue media content that could curve risky factors on building positive body image. This finding indicates that current campaigns and movements on body image have captured the attention of people in need of help. Exposure to this media content acts as a stimulus, which then produces more interpersonal conversation and cognitions. Conversations help people make sense of the media content and encourage and increase awareness of campaign contents and healthy behaviors. Again, sustainability is keenly related to qualities of life or well-being [1]; health campaign designers and individuals would use the current results to generate knowledge and awareness, which will raise an individual's psychological well-being.

Author Contributions: Conceptualization, funding acquisition, investigation, development or design of methodology, creation of models -original draft, E.L.; conceptualization, data curation, resources, validation, writing-review and editing, G.-i.L. All authors have read and agreed to the published version of the manuscript.

Funding: This work was funded by Korean Association for Broadcasting \& Telecommunication Studies under the 2019 project for supporting young researchers.

Institutional Review Board Statement: Ethical review and approval were waived for this study due to expediting procedure under the COVID-19 circumstances.

Informed Consent Statement: Patient consent was waived due to the IRB waiver.

Data Availability Statement: The data presented in this study are available on request from the corresponding author.

Conflicts of Interest: The authors declare that they have no conflict of interest.

\section{References}

1. Kuhlman, T.; Farrington, J. What is sustainability? Sustainability 2010, 3436. [CrossRef]

2. You, S.; Shin, K.; Kim, E.K. The effects of sociocultural pressures and exercise frequency on the body esteem of adolescent girls in Korea. J. Child Fam. Stud. 2018, 27, 26-33. [CrossRef]

3. Kennedy, A.K.; Schneiderman, J.U.; Winter, V.R. Association of body weight perception and unhealthy weight control behaviors in adolescence. Child. Youth Serv. Rev. 2019, 96, 250-254. [CrossRef] 
4. Izydorczyk, B.; Sitnik-Warchulska, K. Sociocultural appearance standards and risk factors for eating disorders in adolescents and women of various ages. Front. Psychol. 2018, 9, 429. [CrossRef]

5. Rodgers, R.F.; McLean, S.A.; Marques, M.; Dunstan, C.J.; Paxton, S.J. Trajectories of body dissatisfaction and dietary restriction in early adolescent girls: A latent class growth analysis. J. Youth Adolesc. 2016, 45, 1664-1677. [CrossRef] [PubMed]

6. Jung, J.; Forbes, G.B. Multidimensional assessment of body dissatisfaction and disordered eating in Korean and U.S. college women: A comparative study. Sex Roles 2006, 55, 39-50. [CrossRef]

7. Kim, S.Y.; Seo, Y.S.; Baek, K.Y. Face consciousness among South Korean women: A culture-specific extension of objectification theory. J. Couns. Psychol. 2014, 61, 24-36. [CrossRef] [PubMed]

8. International Society of Aesthetic Plastic Surgeons. ISAPS International Survey on Aesthetic/Cosmetic Procedures Performed in 2015. 2016. Available online: https://www.isaps.org/wp-content/uploads/2017/10/2016-ISAPS-Results-1.pdf (accessed on 2 November 2020).

9. You, S.; Shin, K. Body esteem among Korean adolescent boys and girls. Sustainability 2019, 11, 2051. [CrossRef]

10. Lee, C. The interplay between media use and interpersonal communication in the context of healthy lifestyle behaviors: Reinforcing or substituting? Mass Commun. Soc. 2010, 13, 48-66. [CrossRef]

11. Viswanath, K. The communications revolution and cancer control. Nat. Rev. 2005, 5, 828-835. [CrossRef] [PubMed]

12. Rimal, R.N.; Flora, J.A.; Schooler, C. Achieving improvements in overall health orientation: Effects of campaign exposure, information seeking, and health media use. Commun. Res. 1999, 26, 322-348. [CrossRef]

13. Seo, M.; Matsaganis, M.D. How interpersonal communication mediates the relationship of multichannel communication connections to health-enhancing and health-threatening behaviors. J. Health Commun. 2013, 18, 1002-1020. [CrossRef]

14. Wirtz, J.G.; Wang, Z.; Kulpavarapos, S. Testing Direct and Indirect Effects of Identity, Media Use, Cognitions, and Conversations on Self-Reported Physical Activity Among a Sample of Hispanic Adults. Health Commun. 2017, 32, 298-309. [CrossRef]

15. Arroyo, A.; Segrin, C.; Harwood, J. Appearance-related communication mediates the link between self-objectification and health and well-being outcomes. Hum. Commun. Res. 2014, 40, 463-482. [CrossRef]

16. Paek, H. Mechanisms through which adolescents attend and respond to anti-smoking media campaigns. J. Commun. 2008, 58, 84-105. [CrossRef]

17. Yoo, J.H. No clear winner: Effects of the biggest loser on the stigmatization of obese persons. Health Commun. 2013, 28, 294-303. [CrossRef]

18. Yoo, J.H.; Tian, Y. Effects of entertainment (mis)education: Exposure to entertainment television programs and organ donation intention. Health Commun. 2011, 26, 147-158. [CrossRef] [PubMed]

19. Lee, E. The effects of family communication and media exposure on high school girls' cosmetic surgery intentions: An exploratory study on the mediating effect of the behavior of appearance internalization, appearance satisfaction, information seeking behavior. Korean J. Broadcasting Telecommun. Stud. 2019, 33, 140-183.

20. Markus, H.; Zajonc, R.B. The cognitive perspective in social psychology. In The Handbook of Social Psychology, 3rd ed.; Lindzey, G., Aronson, E., Eds.; Random House: New York, NY, USA, 1985; pp. 137-230.

21. Fredrickson, B.L.; Roberts, T.A. Objectification theory: Toward understanding women's lived experiences and mental health risks. Psychol. Women Q. 1997, 21, 173.e206. [CrossRef]

22. Thompson, J.K.; van den Berg, P.; Roehrig, M.; Guarda, A.; Heinberg, L. The sociocultural attitudes towards appearance scale-3 (SATAQ-3): Development and validation. Int. J. Eat. Disord. 2004, 35, 293-304. [CrossRef]

23. Tiggemann, M. Television and adolescent body image: The role of program content and viewing motivation. J. Soc. Clin. Psychol. 2005, 24, 361-381. [CrossRef]

24. Clark, L.; Tiggemann, M. Sociocultural and individual psychological predictors of body image in young girls: A prospective study. Dev. Psychol. 2008, 44, 1124-1134. [CrossRef]

25. Jones, D.C.; Vigfusdottir, T.H.; Lee, Y. Body image and the appearance culture among adolescent girls and boys: An examination of friend conversations, peer criticism, appearance magazines, and the internalization of appearance ideals. J. Adolesc. Res. 2004, 19, 323-339. [CrossRef]

26. McLeod, J.M.; Kosicki, G.M.; McLeod, D.M. The expanding boundaries of political communication effects. In Media Effects: Advances in Theory and Research; Bryant, J., Zillman, D., Eds.; Lawrence Erlbaum: Hillsdale, NJ, USA, 1994; pp. $123-162$.

27. McLeod, D.M.; Kosicki, G.M.; McLeod, J.M. Resurveying the boundaries of political communications effects. In Media Effects: Advances in Theory and Research, 2nd ed.; Bryant, J., Zillman, D., Eds.; Erlbaum: Hillsdale, NJ, USA, 2002; pp. $215-267$.

28. McLeod, J.M.; Scheufele, D.A.; Moy, P. Community, communication, and participation: The role of mass media and interpersonal discussion in local political participation. Political Commun. 1999, 16, 315-336. [CrossRef]

29. Holbert, R.L.; Kwak, N.; Shah, D.V. Environmental concern patterns of television viewing, and pro-environmental behavior: Integrating models of media consumption effect. J. Broadcasting Electron. Media 2003, 47, 177-196. [CrossRef]

30. Tian, Y.; Robinson, J.D. Media complementarity and health information seeking in Puerto Rico. J. Health Commun. 2014, 19, 710-720. [CrossRef] [PubMed]

31. Keery, H.; van den Berg, P.; Thompson, J.K. An evaluation of the tripartite influence model of body dissatisfaction and disordered eating with adolescent girls. Body Image 2004, 1, 237-251. [CrossRef] [PubMed]

32. Mazzeo, S.; Trace, S.; Mitchell, K. Effects of a reality T.V. cosmetic surgery makeover program on disordered eating attitudes and behavior. Eat. Behav. 2007, 8, 390-397. [CrossRef] [PubMed] 
33. Menzel, J.E.; Sperry, S.L.; Small, B.; Thompson, J.K.; Sarwer, D.B.; Cash, T.F. Internalization of appearance ideals and cosmetic surgery attitudes: A test of the tripartite influence model of body image. Sex Roles 2011, 65, 469-477. [CrossRef]

34. Shroff, H.; Thompson, J.K. The tripartite influence model of body image and eating disturbance: A replication with adolescent girls. Body Image 2006, 3, 17-23. [CrossRef]

35. van den Berg, P.; Thompson, J.K.; Brandon, K.; Coovert, M. The tripartite model of body image and eating disturbance: A covariance structure modeling investigation. J. Psychosom. Res. 2002, 53, 1007-1020. [CrossRef]

36. Halliwell, E.; Dittmar, H. Associations between appearance-related self-discrepancies and young women's and men's affect, body satisfaction, and emotional eating: A comparison of fixed-item and participant-generated self-discrepancies. Personal. Soc. Psychol. Bull. 2006, 32, 447-458. [CrossRef]

37. Sharpe, H.; Naumann, U.; Treasure, J.; Schmidt, U. Is fat talking a causal risk factor for body dissatisfaction? A systematic review and meta-analysis. Int. J. Eat. Disord. 2013, 46, 643-652. [CrossRef] [PubMed]

38. Nichter, M. Fat Talk: What Girls and Their Parents Say about Dieting; Harvard University Press: Cambridge, MA, USA, 2000.

39. Loth, K.A.; Neumark-Sztainer, D.; Croll, J.K. Informing family approaches to eating disorder prevention: Perspectives of those who have been there. Int. J. Eat. Disord. 2009, 42, 146-152. [CrossRef] [PubMed]

40. Shannon, A.; Mills, J.S. Correlates, causes, and consequences of fat talk: A review. Body Image 2015, 15, 158-172. [CrossRef] [PubMed]

41. Britton, L.E.; Martz, D.M.; Bazzini, D.G.; Curtin, L.A.; Lea, S.A. Fat talk and self-presentation of body image: Is there a social norm for women to self-degrade? Body Image 2006, 3, 247-254. [CrossRef]

42. Martz, D.M.; Petroff, A.B.; Curtin, L.A.; Bazzini, D.G. Gender differences in fat talk among American adults: Results from the psychology of size survey. Sex Roles 2009, 6, 34-41. [CrossRef]

43. Webb, J.B.; Rogers, C.B.; Etzel, L.; Padro, M.P. "Mom, quit fat talking-I'm trying to eat (mindfully) here!": Evaluating a sociocultural model of family fat talk, positive body image, and mindful eating in college women. Appetite 2018, 126, 169-175 [CrossRef] [PubMed]

44. Thompson, J.K.; Heinberg, L.; Altabe, M.; Tantleff-Dunn, S. Exacting Beauty: Theory, Assessment, and Treatment of Body Image Disturbance; American Psychological Association: Washington, DC, USA, 1999.

45. Augustus-Horvath, C.L.; Tylka, T.L. The acceptance model of intuitive eating: A comparison of women in emerging adulthood, early adulthood, and middle adulthood. J. Couns. Psychol. 2011, 58, 110-125. [CrossRef]

46. Moradi, B.; Dirks, D.; Matteson, A. Roles of sexual objectification experiences and internalization of standards of beauty in eating disorder symptomatology: An examination and extension of objectification theory. J. Couns. Psychol. 2005, 52, 420-428. [CrossRef]

47. Tolaymat, L.D.; Moradi, B.U.S. Muslim women and body image: Links among objectification theory constructs and the hijab. J. Couns. Psychol. 2011, 58, 383-392. [CrossRef] [PubMed]

48. Bissell, K.; Rask, A. Real women on Real Beauty: Self-discrepancy, internalization of the thin ideal, and perceptions of attractiveness and thinness in Dove's campaign for Real Beauty. Int. J. Advert. 2010, 29, 643-668. [CrossRef]

49. Millard, J. Performing beauty: Dove's 'Real Beauty' campaign. Symb. Interact. 2009, 22, 146-168. [CrossRef]

50. Cinelli, M.D.; Yang, L. The role of implicit theories in evaluations of 'Plus-Size' advertising. J. Advert. 2016, 45, 472-481. [CrossRef]

51. Fung, Y.; Chen, H.; He, L. Consumer responses to Femvertising: A dat-mining case of Dove's "Campaign for Real Beauty" on YouTube. J. Advert. 2019, 48, 292-301. [CrossRef]

52. Hart, W.; Albarracin, D.; Eagly, A.; Brechan, I.; Lindberg, M.; Merrill, L. Feeling validated versus being correct: A meta-analysis of selective exposure to information. Psychol. Bull. 2009, 135, 555-588. [CrossRef]

53. Hastie, R. Causes and effects of causal attribution. J. Personal. Soc. Psychol. 1984, 47, 44-56. [CrossRef]

54. Hastie, R.; Kumar, A.P. Person memory: Personality traits as organizing principles in memory for behaviors. J. Personal. Soc. Psychol. 1979, 37, 25-38. [CrossRef]

55. Stangor, C.; McMillan, D. Memory for expectancy-congruent and expectancy-incongruent information: A review of the social and social developmental literatures. Psychol. Bull. 1992, 111, 42-61. [CrossRef]

56. Bandura, A. Social Learning Theory; Prentice Hall: Englewood Cliffs, NJ, USA, 1977.

57. Hornik, R.; Yanovitsky, I. Using theory to design evaluations of communication campaigns: The case of the national youth anti-drug media campaign. Commun. Theory 2003, 13. [CrossRef]

58. Sotirovic, M.; McLeod, J.M. Values, communication behavior, and political participation. Political Commun. 2001, 18, 273-300. [CrossRef]

59. Southwell, B.G.; Yzer, M.C. The roles of interpersonal communication in mass media campaigns. In Communication Yearbook; Beck, C., Ed.; Lawrence Erlbaum: New York, NY, USA, 2007; Volume 31, pp. 420-462.

60. van den Putte, B.; Yzer, M.; Southwell, B.G.; de Brujin, G.J.; Willemsen, M.C. Interpersonal communication as an indirect pathway for the effect of anti-smoking media content on smoking cessation. J. Health Commun. 2011, 16, 470-485. [CrossRef] [PubMed]

61. Hwang, H.; Gotlieb, M.R.; Nah, S.; McLeod, D.M. Applying a cognitive-processing model to presidential debate effects: Post debate news analysis and primed reflection. J. Commun. 2007, 57, 40-59. [CrossRef]

62. Rosenberg, M. Self-concept from middle childhood through adolescence. In Psychological Prospective on the Self; Suls, J., Greenwald, A.G., Eds.; Erlbaum: Hillsdale, NJ, USA, 1986; pp. 182-205.

63. Gondoli, D.M.; Corning, A.F.; Salafia EH, B.; Bucchianeri, M.M.; Fitzsimmons, E.E. Heterosocial involvement, peer pressure for thinness, and body dissatisfaction among young adolescent girls. Body Image 2011, 8, 143-148. [CrossRef]

64. Ferguson, C.J.; Winegard, B.; Winegard, B.M. Who is the fairest one of all? How evolution guides peer and media influences on female body dissatisfaction. Rev. Gen. Psychol. 2011, 15, 11-28. [CrossRef] 
65. Trekels, J.; Eggermont, S. Beauty is good: The appearance culture, the internalization of appearance ideals, and dysfunctional appearance beliefs among tweens. Hum. Commun. Res. 2017, 43, 173-192. [CrossRef]

66. Farrelly, M.C.; Davis, K.C.; Haviland, M.L.; Healton, C.G.; Messeri, P. Evidence of a dose-response relationship between "truth" anti-smoking ads and youth smoking prevalence. Am. J. Public Health 2005, 95, 425-431. [CrossRef] [PubMed]

67. Siegel, M.; Biener, L. The impact of an anti-smoking media campaign on progression to established smoking: Results of a longitudinal youth study. Am. J. Public Health 2000, 90, 380-386. [PubMed]

68. McKinley, N.; Hyde, J. The Objectified Body Consciousness scale: Development and validation. Psychol. Women Q. 1996, 20, 181-215. [CrossRef]

69. Moradi, B. Addressing gender and cultural diversity in body image: Objectification theory as a framework for integrating theories and grounding research. Sex Roles 2010, 63, 138-148. [CrossRef]

70. Hu, L.T.; Bentler, P.M. Cutoff criteria for fit indexes in covariance structure analysis: Conventional criteria versus new alternatives. Struct. Equ. Model. 1999, 6, 1-55. [CrossRef]

71. Kluck, A.S. Family influence on disordered eating: The role of body image dissatisfaction. Body Image 2010, 7, 8-14. [CrossRef] [PubMed]

72. Rodgers, R. Body image: Familial influences. In Encyclopedia of Body Image and Human Appearance; Cash, T.F., Ed.; Academic Press: Cambridge, MA, USA, 2012; Volume 1, pp. 219-225.

73. Rodgers, R.; Chabrol, H. Parental attitudes, body image disturbance and disordered eating amongst adolescents and young adults: A review. Eur. Eat. Disord. Rev. 2009, 17, 137-151. [CrossRef] [PubMed]

74. Levine, M.P.; Smolak, L. Recent developments and promising directions in the prevention of negative body image and disordered eating in children and adolescents. In Body Image, Eating Disorders, and Obesity in Youth: Assessment, Prevention, and Treatment, 2nd ed.; Smolak, L., Thompson, J.K., Eds.; American Psychological Association: Washington, DC, USA, 2009; pp. $215-239$.

75. Schutz, H.K.; Paxton, S.J.; Wertheim, E.H. Investigation of body comparison among adolescent girls. J. Appl. Soc. Psychol. 2002, 32, 1906-1937. [CrossRef]

76. Thompson, J.K.; Cattarin, J.; Fowler, B.; Fisher, E. The Perception of Teasing Scale (POTS): A revision and extension of the Physical Appearance Related Teasing Scale (PARTS). J. Personal. Assess. 1995, 65, 146-157. [CrossRef] [PubMed] 